\title{
Engaging Users with an AR Pervasive Game for Personal Urban Awareness
}

\author{
Mónica Sánchez-Francisco \\ Computer Sciences Department \\ Universidad Carlos III \\ Spain \\ mosanche@inf.uc3m.es \\ Federico Fabiano \\ OneDay Group S.r.1 \\ Italy \\ iamfedericofabiano@gmail.com
}

\author{
Paloma Díaz \\ Computer Sciences Department \\ Universidad Carlos III \\ Spain \\ pdp@inf.uc3m.es \\ Ignacio Aedo \\ Computer Sciences Department \\ Universidad Carlos III \\ Spain \\ aedo@inf.uc3
}

\begin{abstract}
The combination of Augmented Reality (AR) and pervasive games in urban environments offers a great opportunity for learning about a specific urban environment. Since pervasive games are played in a physical space, the user familiarity with such environment might play a key role in the user motivation and in the whole user experience. In this paper, we analyse how an augmented reality pervasive game is experienced in an urban game. The aim of the game is to engage people in informal learning activities increasing their knowledge about a specific area. We also introduce the concept of Personal Urban Awareness (PUA) as a way to represent the level at which a person feels connected and knows about a specific environment. Thus, we try to find out whether the user engagement and PUA are related. In order to research this, we run an experiment where two groups of users, familiar with the environment and not familiar with it, play the augmented reality game in an urban space. The results suggest that AR pervasive games might be a good approach to engage citizens and improve their awareness about a specific area.
\end{abstract}

\section{CCS CONCEPTS}

Human Computer Interaction $\rightarrow$ Pervasive Game; Augmented Reality; User studies;

\footnotetext{
Permission to make digital or hard copies of all or part of this work for personal or classroom use is granted without fee provided that copies are not made or distributed for profit or commercial advantage and that copies bear this notice and the full citation on the first page. Copyrights for components of this work owned by others than the author(s) must be honored. Abstracting with credit is permitted. To copy otherwise, or republish, to post on servers or to redistribute to lists, requires prior specific permission and/or a fee. Request permissions from Permissions@acm.org. Interacción 2019, June 25-28, 2019, Donostia, Gipuzkoa, Spain

(C) 2019 Copyright is held by the owner/author(s). Publication rights licensed to ACM. ACM ISBN 978-1-4503-7176-6/19/06 \$15.00 https://doi.org/10.1145/3335595.3335630
}

\section{KEYWORDS}

Pervasive Games; Playable Cities; Augmented Reality; Urban Environment; User Engagement.

\section{ACM Reference format:}

Monica Sanchez-Francisco, Federico Fabiano, Paloma Díaz and Ignacio Aedo. 2019. Engaging Users with an AR Pervasive Game for Personal Urban Awareness. In Proceedings of XX International Conference on Human Computer Interaction (Interacción 2019), June 25-28, 2019, Donostia, Gipuzkoa, Spain. ACM, New York, NY, USA, 7 pages. https://doi.org/10.1145/3335595.3335630

\section{Introduction}

According to the United Nations Department of Economic and Social Affairs (UN DESA), our future will be urban. By 2030, 43 cities around the world will have 10 million or more inhabitants [28]. This trend points directly to the importance of solving complex problems that cities are going to face in a very near future [8]. How to manage many of these issues is directly related to datadriven systems and technological driven solutions usually referred as the Smart City. However, Smart Cities received some criticism $[1,11]$ and an alternative notion called "Playable Cities" emerged $[16,19]$. This concept shifted the focus from the data-driven approach to a citizen-centred one. The purpose of this initiative is to engage people with games and playful activities in the citymaking process as well as improve their knowledge and the cohesion in the city.

Mobile pervasive applications provide the technological platform to develop games that support more interactive experiences in playful smart cities [9]. Moreover, pervasive games can be used for several serious purposes. For example, urban exploration [18], to increase the students engagement in the learning process [17] and also for improving the people motivation to learn about the 
surroundings [2]. Most of such pervasive games are played on the smartphone which integrates functionalities such as GPS, compass and wireless connection and, in turn, these technologies support the portability of the device and, consequently, a pervasive approach. The usage of the combination of Augmented Reality (AR) and pervasive games in urban context provides a great opportunity for learning about a specific urban environment. In this work, we investigate whether using this type of applications can be exploited to learn about the history of one urban environment, in our case, a historical building of our university which mostly goes unnoticed by the students.

In the context of pervasive games, there is a strong link between the digital game and the physical space. Therefore, the user's familiarity with the environment, which is the playground in pervasive games, plays an important role within the game, influencing the user motivation and the whole user experience. Thus, we introduce the concept of Personal Urban Awareness (PUA) as a way to represent the level at which a person feels connected and knows about a specific environment.

Moreover, we want to research whether there is a connection and a relation between the PUA and the level user engagement. In order to do so, we carried out an experiment that compares two different participant profiles playing the same game, familiar with the playground and those who are not familiar with it.

To sum up, the research aims at answering two questions:

Research Question 1 (RQ1): To what extent the familiarity with the environment influences the user engagement?

Research Question 2 (RQ2): To what extent Personal Urban Awareness has an impact on the user engagement?

The paper is organized as follows. Section 2 introduces the background of this research. Section 3 describes the AR pervasive game that will be used in the empirical study. Next section describes the experiment whose results are analysed in section 5 . The paper ends with drawing some conclusions of the work, the limitations of the experiment and what could be the future steps in the investigation.

\section{Background}

Seeing the cities through the perspective of people is in the core of the Playable Cities concept $[16,19]$. This initiative encourages the development of playful and engaging experiences for citizens in the urban spaces. The aspiration is to promote the participation of citizens in urban planning, improve the general sense of community, support informal learning and increase the feeling of belonging and caring of urban areas $[6,16,19]$. For achieving these goals, pervasive games are adopted because they can generate a tight connection with the physical environment [13] and they provide a powerful play experience [16]. Moreover, playing with this type of games has benefits in terms of users well-being [10] and social interactions [12]. Many mobile pervasive games have been used to engage people in healthier habits and produce a more ethical and collaborative behaviour in society. For instance, Gamifying the City [3] wants to improve the citizens general wellbeing by making them play while participate in the urban design in a collaborative way. Another relevant example is Chronica Mobilis [24] that tries to bring attention to the gentrification of one neighborhood in the city of Barcelona.

When augmented reality (AR) is added to pervasive games, the resulting experience benefits from the combination of superimposing digital information into the physical environments where the game is played and the portability of the technology. The consequence is an engaging and playful context [16]. In fact, it has been proved that $\mathrm{AR}$ is a useful way to contextualize information in the physical world $[5,14]$ and a valuable approach to engage citizens $[2,3]$ which in turn affects positively the user experience. These AR urban games offer a new way to get to know the city in different ways [4] by adding new meanings to the environment and involving citizens in the public life while playing [3].

Our work reflects on how pervasive games could be used to learn about a particular urban environment and how the gaming experience could affect our perception of a physical space. In particular, we aim at understanding if the players' familiarity with the environment affects their engagement while playing with the game. In addition to this, pervasive games in the context of playable cities also aim at raising awareness about the urban spaces, therefore, we want to use this approach in order to improve the perception of a certain space by using the game. With this purpose, we introduce and measure the concept of Personal Urban Awareness (PUA). This concept is rooted in two notions, one is the Environmental Education and the other one is Local Awareness. Environmental Education was introduced by Stapp [27] to represent how citizens are more motivated to improve their environment if they are aware and educated about it. Instead, the concept of Local Awareness is related with the idea of awareness of Schmid [25]. He explains the notion of awareness as an attribute of an action. Where the actor of the action aligns and integrate their activities with their context, without interrupting the current line of action and in a seemingly effortless way. If we transpose this concept in the context of AR pervasive games, it could be the action of searching a virtual object with the AR layer in the real world and at the same time know more the physical space. For instance, PUA will be then the active process through which users acquire knowledge and interest about a specific urban environment while they are playing with a pervasive application.

\section{A Pervasive Game for Urban Awareness}

In order to understand whether pervasive AR games could be used to improve citizen awareness of a specific urban context and to evaluate the impact of the users' familiarity with the environment on the user, we developed a mobile $\mathrm{AR}$ pervasive game in the 
context of our university. The game has been already introduced in [23].

The aim of the game is to connect university students with the historical context of one of the buildings in our campus. The campus is located in a suburban area with a particular historical interest. However, most inhabitants and specially students to not pay attention to the historical roots of the city.

\subsection{Scenario of the Game}

The game describes the period of the Spanish Independence war (Uprising of $2^{\text {nd }}$ of May). This war took place in 1808 and at this time the Sabatini building, which is the main building of the campus, was occupied by the French Hussar Regiment. The users play the role of the citizens of the town and their goal is to help to assault the Sabatini building to liberate it from the French army. In order to help, players are requested to collect the pieces of a cannon that are scattered around the building. In order to collect a cannon piece, they need to locate it on the top-view map (see Figure 1) and walk towards its position. Once they reach the exact position they have to answer a question related to the historical context of the building and the events that happened there. When they have picked up all the cannon pieces, they can mount the cannon and shoot it towards the building, then one round of the game is considered completed.

\subsection{Game Mechanics and UI}

At the beginning of the game, a brief introduction to the historical context and an explanation of the main interactions of the game is given to the player. After that, users need to search for the first cannon piece with help of the top-view map provided in the game interface (see Figure 1). There isn't a pre-defined order in the collection of the objects, the player decides freely how to explore the surroundings. Every player starts the game on the same spot in order to avoid biases on the path to chose. The cannon pieces are virtual objects placed around the player with a real reference to the real-world using AR.

In order to pick up the pieces, the player has to be close enough to the area where the object is located. At this moment, a question concerning the surrounding appears on the screen and the player has to answer. Right after, a short explanation of the question is shown to promote learning about the surroundings (see Figure 2). After that, the player has to virtually collect the piece through an $A R$ view. The user sees a virtual layer with the piece in the real environment (see Figure 1).

Once the players have collected all the five pieces, they need to walk towards the shooting point where they can mount the cannon and shoot it. There is an explanatory video that shows the process and the interactions of the game ${ }^{1}$.

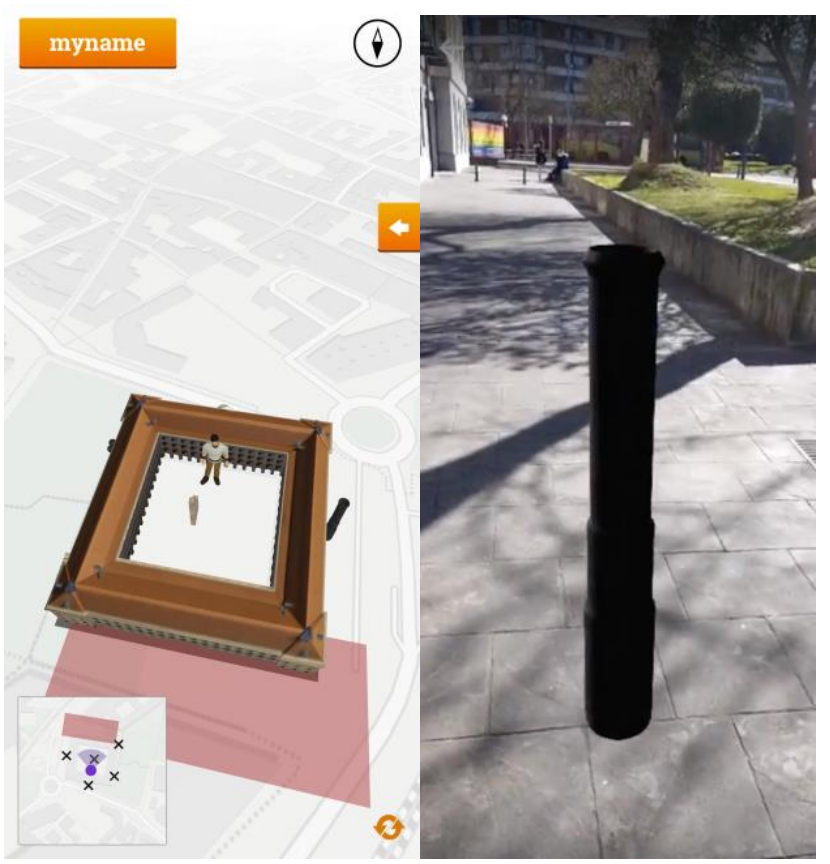

Figure 1: The AR pervasive game. On the left the general interface; On the right the AR view.

The user interface was designed paying special attention to the aesthetics of the game as a factor that can influence the user engagement [21]. A deeper explanation of the game design can be found in [23]. The usability, the safety and the technical limitations of the game were evaluated in a usability study [7]. The results of the study confirmed that the system was perceived as highly usable and safe to play in the chosen environment.

\section{Experiment}

This experiment aims at contributing to the definition of a theoretical framework for the evaluation of the engagement of pervasive games in the context of playable cities. This contribution consists of two steps: first, evaluating the User Engagement and see whether it is influenced by the users' familiarity with the surroundings. Second, assessing the PUA and checking whether PUA is correlated with user engagement.

The method chosen for the assessment of the experiment is a selfreported measurement, namely a combination of questionnaires as described below.

${ }^{1}$ www.youtube.com/watch?v=LttUqsSYt70 


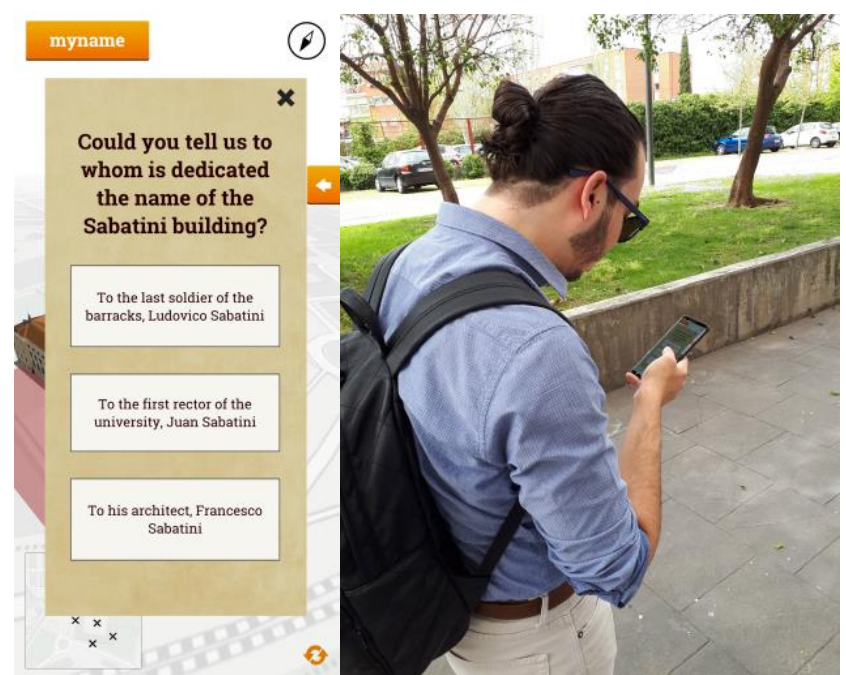

Figure 2: On the left a question related to the building; On the right a player answering the question.

\subsection{Study Design}

The experiment follows a between-subjects design where the same condition is evaluated with two different types of users: people who are not familiar with the campus, that is, who have never been there or up to 5 times; and, people who are familiar with the environment, namely people who are in the campus on a regular basis (e.g. weekly or daily). The recruitment followed a convenience sampling approach and the unique requirement for participating in the study was to belong to one of the two groups.

\subsection{Participants}

27 participants were recruited for the experiment. 13 users were in the not familiar condition and 14 familiar. Among the 27 participants, 15 users were males (55.6\%) and 12 females $(44.4 \%)$. Concerning their experience with AR technology, 15 users were beginners (i.e. has used AR pervasive games less than 6 times before the experiment), and 12 were expert users. The majority of the users fits in the age range of 18-24 years old $(n=16), 8$ participants are in the range of 25-34 years, 2 users in the 35-50 range and only one was under 18 .

\subsection{Apparatus}

The game has been implemented in Unity using Vuforia ${ }^{2}$ for the AR interactions and it is developed for Android devices (Android 8.0). The application uses the GPS to track the players' position and the compass to orient them in the map.

\subsection{Procedure}

The experiment was carried out in the Sabatini building, the main building in the university campus of the Universidad Carlos III de Madrid.

Firstly, participants were asked to sign an informed consent that stated their participation was voluntary and the collected data were anonymised and only used for research purposes following the process approved by the ethics committee.

Afterwards, a researcher explained the game and provided users with a smartphone with the game. Participants started to play all in the same location of the campus. They were asked to play one full round of the game and, subsequently, to fill the questionnaires in the laboratory.

\subsection{Material}

The combination of questionnaires aims at assessing different criteria in the two conditions. In particular, the following criteria were assessed:

- Demographics. The questionnaire included 5 general questions about the background of the participants concerning their age, gender, level of education, familiarity with the campus and previous experience with AR pervasive games.

- User Engagement. The most common self-reported measurement to assess the user engagement is the User Engagement Scale (UES) [20]. However, the combination of several questionnaires leads to a considerably high number of items requiring an excessive effort for participants. Therefore, we decided to opt for the UES-Short Form [22], which has been proved to be a shorter and more flexible version.

- Personal Urban Awareness. This part consisted of a 3questions survey (see Table 1) meant to assess the level of PUA in terms of the attachment to the university environment. In a second moment, we investigate whether this theme influences the user engagement comparing the two groups, Familiar and Not familiar.

Table 1: Items of the PUA questionnaire.

\begin{tabular}{|l|l|}
\hline ID & Items \\
\hline PUA 1 & $\begin{array}{l}\text { After playing the game I feel more attached to this } \\
\text { environment. }\end{array}$ \\
\hline PUA 2 & $\begin{array}{l}\text { After playing the game I feel more connected to the } \\
\text { university. }\end{array}$ \\
\hline PUA 3 & $\begin{array}{l}\text { I would like to use Augmented Reality games to be } \\
\text { more aware about any urban environment that } \\
\text { surrounds me. }\end{array}$ \\
\hline
\end{tabular}

\footnotetext{
${ }^{2}$ www.vuforia.com/
} 


\section{Results}

\subsection{User Engagement Evaluation}

The answers of the UES-SF questionnaire [22] are measured in a 5-point Likert scale (1=strongly disagree, 5=strongly agree). Each question has a score and it's categorized within the different categories of the User Engagement (namely, Focused Attention, Perceived Usability, Aesthetics and Reward). In order to calculate the score for each user we use the UE General, which is the average between the categories' scores [22].

In general, the results of the UES-SF are positive. The average of the UE General scores is 3,836 out of 5 ( $\mathrm{SD}=0,46$ ). Nevertheless, if the scores are analysed by categories, they are notably different, as shown in Figure 3. The highest score belongs to the category Perceived Usability $(4,6 / 5 ; \mathrm{SD}=0,52)$ due to the fact that a usability study was carried out before the experiment [7]. Conversely, the lowest results with a higher Standard Deviation were obtained for the Focused Attention (3,160/5; $\mathrm{SD}=0,87)$. The remaining categories scored positively, Aesthetic category has an average score of 3,605 out of $5(\mathrm{SD}=0,67)$ and the Reward category scored 3,975 out of $5(\mathrm{SD}=0,58)$.

If the UE General scores are compared according to the two conditions, familiar users scored on average $3.7(\mathrm{SD}=0,42)$ and the not Familiar participants $3.955(\mathrm{SD}=0,49)$. There is not a statistically significant difference between the two sets, in fact, the $\mathrm{p}$-value obtained through ANOVA test is above $0,05(\mathrm{p}=0,2)$. Consequently, we cannot state that familiarity has an impact in user engagement.

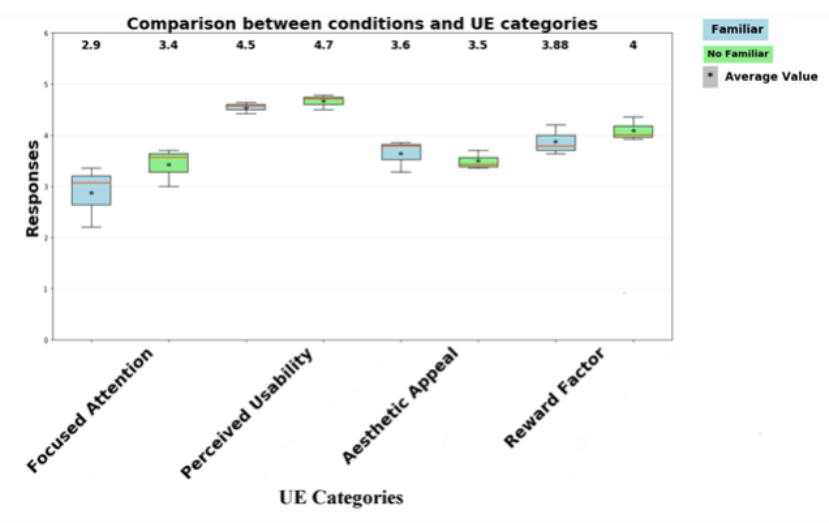

Figure 3: On Results of the UES-SF questionnaire divided by categories.

\subsection{Personal Urban Awareness}

The reliability of the PUA questionnaire has been evaluated through the Cronbach's Alpha $(\alpha=0,58)$. The results show that it is lower than the acceptability threshold, set at 0.7 by the rule of thumb $[15,26]$. However, the correlation between PUA3 and the

other two items (PUA1 and PUA2) is pretty low. This might suggest that the question PUA3 was perceived with a different meaning by users. As a matter of fact, if only PUA1 and PUA2 are considered for the calculation of the internal reliability, the value of alpha increases to 0,65 .

The results of the PUA questionnaire are mostly positive (avg=3,65/5) as shown in Figure 4. Nonetheless, two users' scores are negative (i.e. lower than 3 ) and one neutral (i.e. equals to 3 ). Subsequently, we calculated the Pearson Correlation Coefficient to examine whether there is a correlation between the UE General and the PUA. There is a weak positive correlation between the two sets $(\mathrm{r}=0,32)$.

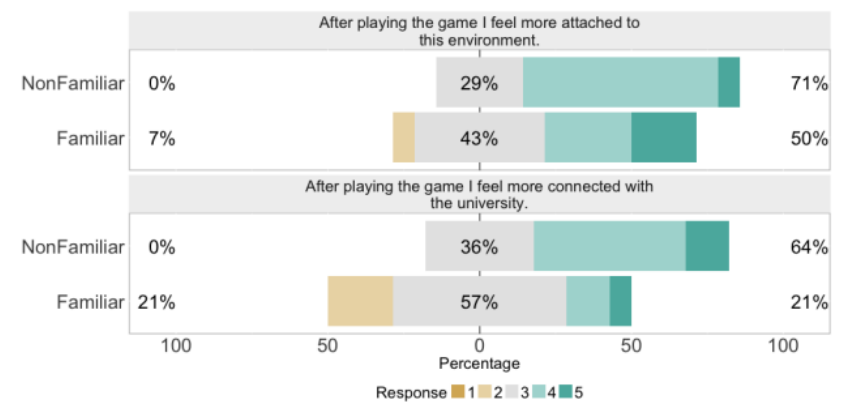

Figure 4: Results of the PUA1 and PUA2 questionnaire divided by familiarity categories

The increase of the reliability when considering only the questions PUA1\&PUA2 gives us an insight that PUA3 might have been misinterpreted. Therefore, we analysed the results without considering the question, the average of the final scores is 3,59 out of 5 and the correlation between PUA and the user engagement rises $(r=0,593)$ with the increase of the reliability (from 0,58 to $0,65)$.

\section{Discussion}

Despite the differences between the categories of the UES-SF, we can deduce that the AR pervasive game engaged positively users who played with it during the experiment. The result of the category Focused Attention, which is the lowest score, is coherent with the type of game. In fact, pervasive games are played in an urban context and, therefore, for safety reasons they require attention to the events that happen in the playground.

The results of the PUA questionnaire show that playing with the game enhances the participants' Personal Urban Awareness. In other words, after playing the game, participants felt more connected to the university by knowing more about its historical events and facts about the main building. The PUA questionnaire items need further refinement since they are not reliable, largely because the PUA3 has been misinterpreted by participants. 
The correlation between the User Engagement and the Personal Urban Awareness is weak. Therefore, at the moment we cannot conclude that PUA is influencing directly the User Engagement in the context of AR pervasive games. However, further analysis revealed a promising trend: with the increase of the scale reliability, the correlation between the two sets of data grew.

The main limitation of the experiment lies on the proposed PUA questionnaire reliability. In fact, the Cronbach's Alpha shows that the methodology is not completely solid. Another limitation lies on the variety of the participants since the group was not well balanced in terms of age. Probably, with a wider range of age would give a broader perspective on the target population for this kind of pervasive game.

\section{Conclusions and future works}

In this paper, we describe the use of an AR pervasive game for improving the awareness of the urban surroundings by learning about the history of the university buildings with a playful approach. This research exemplifies how the user engagement and the personal urban awareness can be assessed adopting userreported measurements in the context of AR pervasive games. The results show that there are some insights that could indicate that PUA has an impact on the user engagement (RQ2).

As far as the evaluation of the game is concerned, it has been perceived as engaging by the participants according to the results of the UE-SF questionnaire. In fact, the results show that there aren't negative or neutral scores. In addition to this, the evaluation of the game demonstrated that the game helped to create a tighter connection between participants and the explored environment, that is the game playground.

The comparison between familiar and not familiar participants shows that not familiar users are more engaged while playing the game, though, there aren't significant differences between the two types of subject (RQ1).

The data analysis brought to the conclusion that the reliability of the adopted questionnaire has been affected by the miscomprehension of the item PUA3. As a next step in the research, we want to improve the PUA questionnaire reliability by adding new items and improving the older ones.

Further, we want to improve the game experience and develop a collaborative version of the game in order to investigate whether playing with other work as a catalyst for the PUA and improves the sense of belonging to a specific urban environment.

\section{ACKNOWLEDGMENTS}

This work was supported by the Spanish Ministry of Economy and Competitiveness Project TIN2016-77690-R "PACE.

\section{REFERENCES}

[1] Bianchini, D. and Ávila, I. 2014. Smart cities and their smart decisions: Ethical considerations. IEEE Technology and Society Magazine. 33, (2014), 34-40. DOI:https://doi.org/10.1109/MTS.2014.2301854.

[2] Bursztyn, N. et al. 2017. Increasing undergraduate interest to learn geoscience with GPS-based augmented reality field trips on students' own smartphones. GSA Today. 27, 6 (2017), 4-10. DOI:https://doi.org/10.1130/GSATG304A.1.

[3] Calafiore, A. and Rapp, A. 2016. Gamifying the city: Pervasive game elements in the urban environment. CEUR Workshop Proceedings. 1715 , (2016).

[4] Chang, M. et al. 2005. Engaging the city. CHI'05 extended abstracts on Human factors in computing systems - CHI '05. (2005), 2109. DOI:https://doi.org/10.1145/1056808.1057110.

[5] Cheok, A.D. and Nilsen, T. 2005. Pervasive Games: Bringing Computer Entertainment Back to the Real World. Computers in Entertainment Theoretical and Practical Computer Applications in Entertainment. 3, 3 (2005), 1-19. DOI:https://doi.org/10.1145/1077246.1077257.

Coulton, P. et al. 2017. Mapping the Beach Beneath the Street: Digital Cartography for the Playable City. Playable C, (2017), 137-162. DOI:https://doi.org/10.1007/978-981-10-1962-3.

[7] Fabiano, F. et al. 2018. Evaluating a pervasive game for urban awareness. Proceedings of the 20th International Conference on Human-Computer Interaction with Mobile Devices and Services Adjunct, MobileHCI 2018, Barcelona, Spain, September 03-06, 2018. (2018), 197-204. DOI:https://doi.org/10.1145/3236112.3236140.

[8] Fernández-Güell, J.M. et al. 2016. Incorporating a Systemic and Foresight Approach into Smart City Initiatives: The Case of Spanish Cities. Journal of Urban Technology. 23, 3 (2016), 43-67. DOI:https://doi.org/10.1080/10630732.2016.1164441.

[9] Fischer, P.T. and Hornecker, E. 2017. Playable Cities. (2017), 163-185. DOI:https://doi.org/10.1007/978-981-10-1962-3.

[10] Florian J. Zach and Iis P. Tussyadiah 2017. To Catch Them All-The (Un)intended Consequences of Pokémon GO on Mobility, Consumption, and Wellbeing. Information and communication technologies in tourism. (Feb. 2017), 217-227.

[11] Hollands, R.G. 2008. Will the real smart city please stand up? Intelligent, progressive or entrepreneurial? City. 12, 3 (2008), 303-320. DOI:https://doi.org/10.1080/13604810802479126.

[12] Kari, T. et al. 2017. Behavior change types with Pokémon GO. Proceedings of the International Conference on the Foundations of Digital Games - FDG '17. November (2017), 1-10. DOI:https://doi.org/10.1145/3102071.3102074

[13] Kasapakis, V. et al. 2013. Pervasive games research. Proceedings of the 17th Panhellenic Conference on Informatics - PCI '13. September (2013), 152. DOI:https://doi.org/10.1145/2491845.2491874.

[14] Kasapakis, V. et al. 2013. Pervasive games research. Proceedings of the 17th Panhellenic Conference on Informatics - PCI '13. November 2014 (2013), 152. DOI:https://doi.org/10.1145/2491845.2491874.

[15] Kline, P. 1994. An easy guide to factor analysis. Personality and Individual Differences. (1994). DOI:https://doi.org/10.1016/0191-8869(94)90040-X.

[16] de Lange, M. 2015. The Playful City: Using Play and Games to Foster Citizen Participation.

[17] López, J.A. et al. 2018. Using pervasive games as learning tools in educational contexts: a systematic review. International Journal of $\begin{array}{llllll}\text { Learning Technology. } & 13, & 2 & \text { (2018), } & 93 .\end{array}$ DOI:https://doi.org/10.1504/ijlt.2018.092094.

[18] Munters, G.M. 2017. PLAYFUL MEDIATION OF PERCEPTION AND ENGAGEMENT. Urban Space and Location-based Augmented Reality Application through the Lens of Play.

[19] Nijholt, A. 2017. Towards playful and playable cities. Springer.

[20] O'Brien, H. L., \& Toms, E.G. 2010. The Development and Evaluation of a Survey to Measure User Engagement. Journal of the Association for Information Science and Technology. 61, 1 (2010), 50-69. DOI:https://doi.org/10.1002/asi.

[21] O'Brien, H. L., \& Toms, E.G. 2008. What is User Engagement? A Conceptual Framework for Defining User Engagement with Technology. Journal of the Association for Information Science and Technology. 59, 6 (2008), 938-955. DOI:https://doi.org/10.1002/asi.

[22] O'Brien, H.L. et al. 2018. A practical approach to measuring user engagement with the refined user engagement scale (UES) and new UES short form. International Journal of Human Computer Studies. 112, July 2017 (2018), 28-39. DOI:https://doi.org/10.1016/j.ijhcs.2018.01.004.

[23] Sánchez-Francisco, M. et al. 2018. Improving Urban Environment Awareness Through Pervasive AR Games. Proceedings of the 2018 International Conference on Advanced Visual Interfaces. (2018), 82:1-82:3. DOI:https://doi.org/10.1145/3206505.3206586.

[24] Santos, V. and Burguès, R.P. 2018. Authoring a serious pervasive game for 
reflecting upon urban spaces. Lecture Notes of the Institute for Computer Sciences, Social-Informatics and Telecommunications Engineering, LNICST (2018), 74-84.

[25] Schmidt, K. 2004. The Problem with "Awareness": Introductory Remarks on 'Awareness in CSCW.' Computer Supported Cooperative Work 11: December (2004), 285-298. DOI:https://doi.org/10.1023/A:1021272909573.

[26] Sekaran, U. 2006. Research Methods for Business. A Skill Building Approach (5th ed.).

[27] Stapp, W.B. 1969. The Concept of Environmental Education. Environmental Education. DOI:https://doi.org/10.1080/00139254.1969.10801479.

[28] World Urbanization Prospects: The 2018 Revision: https://population.un.org/wup/. Accessed: 2019-02-20. 